www.periodicos.unimontes.br/index.php/caminhosdahistoria

\title{
O "MAL DE ALZHEIMER NACIONAL": ALGUMAS REFLEXÕES SOBRE OS USOS POLÍTICOS DO PASSADO E O ENSINO DE HISTÓRIA
}

\author{
Vera Lúcia Silva Vieira ${ }^{1}$ \\ Radamés Vieira Nunes ${ }^{2}$
}

Resumo: O objetivo é trazer a lume algumas reflexões sobre as relações entre presente e passado, memória e história, pensando os caminhos da prática historiográfica e o ensino de história frente aos recorrentes usos políticos do passado e aos ataques e demandas negacionistas na contemporaneidade brasileira. Contrapondo as múltiplas violências visíveis e in(visíveis) na sociedade, destacamos a força da literatura e a dimensão ética, sensível, política e estética da historiografia e do ensino de história como possibilidades de constituição de um repertório mais humano e ético numa cultura marcada por tradições autoritárias e pela violência, negação e apagamento dos rastros dessa mesma violência.

Palavras-chave: Memória; temas sensíveis; temporalidades; ensino de história; ética.

Abstract: The objective is to bring some reflections on the relations between the present and the past, memory and history, thinking about the paths of historiographical practice and the history teaching in the face of the recurring political uses of the past and the attacks and denialist demands in Brazilian contemporary. Opposing the multiple visible and in (visible) violence in society, we highlight the strength of literature and the ethical, sensitive, political and aesthetic dimension of historiography and the history teaching as possibilities for building a more human and ethical repertoire in a culture highligted by authoritarian traditions and by the violence, denial and erasure of the tracks of that same violence.

Keywords: Memory; sensitive topics; temporalities; history teaching; ethic.

O passado traz consigo um índice misterioso, que o impele à redenção. Pois não somos tocados por um sopro do ar que foi respirado antes? Não existem, nas vozes que escutamos, ecos de vozes que emudeceram? Não têm as mulheres que cortejamos irmãs que elas não chegaram a conhecer? Se assim é, existe um encontro marcado entre as gerações precedentes e a nossa.

Walter Benjamin, Sobre o conceito de história.

A epígrafe que abre o texto pode remeter-nos ao encontro entre presente e passado, à fragilidade de suas fronteiras, possibilitando a reflexão sobre o encontro de gerações, as precedentes e a nossa. O que, nos termos de Jörn Rüsen (2011), indica a relação entre a nossa vida no presente e os seres humanos do passado, na medida que vivemos em mediação com o

\footnotetext{
${ }^{1}$ Doutora em História pela UNESP. Professora INHCS/UFG/UFCAT em transição. E-mail: veravieira@ufg.br. ORCID: https://orcid.org/0000-0002-1368-7855.

${ }^{2}$ Doutor em História pela UFU. Professor INHCS/UFG/UFCAT em transição. E-mail: radamesnunes@ufg.br ORCID: https://orcid.org/0000-0002-3628-1866.
} 
mundo que nos foi legado, com os sentidos e o agir dos sujeitos do passado. Somos o resultado das gerações que nos precederam. Herdamos delas um passado que nem sempre queremos. $\mathrm{O}$ que diz respeito às condições de sensibilidade do passado, daquilo que pode torná-lo "imediata e intuitivamente presente" (GUMBRECHT, 2016, p. 42) e que, muitas vezes, sinaliza tensões e angústias, despertando sentimentos de desconforto, nuances que desafiam o poder de discernimento e que nem sempre se pode descrever com precisão.

Perspectiva que atravessa de forma incisiva o romance A resistência de Julian Fuks, em particular, na inquietante indagação: "Pode um exílio ser herdado?” (FUKS, 2015, p.19). A narrativa impulsiona a busca pelo passado carregado de incertezas e examina as dimensões do trauma e da memória inseridos no contexto das ditaduras latino-americanas (perseguições, exílio, abandono, desaparecimentos). Os silêncios e os percursos da memória afetiva e lacunar mobilizam histórias pessoais acrescidas das turbulências experimentadas também na esfera social, na tensão e incapacidade de encontrar uma relação segura e estável com o passado:

Sou eu, não ele, que desejo encontrar um sentido, sou eu que desejo redimir minha própria imobilidade, sou eu que quero voltar a pertencer ao lugar a que nunca pertenci. Entendendo enfim, situado enfim, decido enfim partir: nada me restituirá lugar algum, nada reparará o que vivi, pois não parece haver nada a ser reparado em mim (FUKS, 2015, p.131).

O passado é inevitável e conflituoso, como lembra-nos Beatriz Sarlo (2007). Ele irrompe independentemente da vontade e da razão e sua força não pode ser suprimida senão pela violência, pela ignorância ou pela destruição simbólica e material, o que nem sempre se efetiva. Elisabeth Roudinesco (2006, p.10), ao analisar a relação do historiador com o arquivo, retoma o genocídio dos judeus pelo nazismo. Tudo foi feito para que os vestígios desse ato fossem apagados e silenciados e, no entanto, ele retornou onde não era esperado, pela "força da palavra e do testemunho".

Um dos aspectos que atravessam o ofício do historiador é pensar as dimensões éticas e a responsabilidade social e coletiva que envolve as formas pelas quais a nossa sociedade lida com seus passados, relações vicejadas tomando por entendimento as múltiplas temporalidades entrelaçadas, afinal as diferentes dimensões do tempo só podem ser pensadas se articuladas como partes indissociáveis. Preocupação fundamental que impõe a reflexão sobre os caminhos atuais, sobre a intolerância e o autoritarismo crescente no Brasil e as expectativas de futuro que se abrem (ou se fecham).

Como nos diz Fernando Nicolazzi (2017, p, 8), são muitas as maneiras pelas quais o passado atormenta o presente como "memória que não descansa", uma "lembrança não apaziguada". Nos traços de uma cultura política autoritária, encontra-se o elogio criminoso da 
tortura e da intervenção militar, torturadores homenageados e indivíduos que ocupam altos cargos no governo fazendo usos insustentáveis do passado. Casos em que o vivido retorna como estratégia política, pela disseminação de fake news e manipulação do passado. O que se vislumbra é um passado vivo, impertinente, como herança que nos resta de passados autoritários e inconclusos. Tensões que conferem visibilidade aos dilemas e problemas do passado/presente e implicam diferentes formas de projetar o futuro, como se algo "desse passado e de como se tornou parte do nosso presente nunca terá sossego" (GUMBRECHT, 2014, p.50). ${ }^{3}$

Ainda hoje estão em disputa diversas narrativas e memórias que envolvem diferentes eventos traumáticos do século XX, como os genocídios judeu e armênio, o exílio, a tortura e os desaparecimentos políticos na América Latina, dentre outros. Nesse sentido, é necessário refletir e problematizar o quanto esse passado ainda é constituidor dos modos de criar nossas relações no presente (PEREIRA, 2017), bem como de criar práticas que tendem a silenciar as violências perpetradas e investir na reformulação do passado e apagamento da história.

Questões socialmente vivas e que informam temas controversos, inconclusos, abertos e inquietantes, aspectos que envolvem a responsabilidade ética e social em relação ao presente, mas também em relação ao passado e futuro, bem como a contínua tarefa de elaboração do passado e reescrita da história. Para Durval Muniz Albuquerque Júnior (2012, não p.), os historiadores devem ser "agentes do luto social”, devem lutar contra a cegueira social, contra a vontade de amnésia, o desejo e força sem limites de nossa sociedade em esquecer, em não inscrever (ou inscrever de forma frágil) na consciência coletiva, no espaço público e nas memórias, "os fatos e feitos pouco abonadores de nossas elites dirigentes". Chama a atenção a força das palavras, o trabalho de elaboração do luto em relação ao passado que deve ser realizado pelo esforço de compreensão e esclarecimento do passado, mas sem negligenciar a ação e a intervenção no presente.

Entre nós, a ditadura civil-militar de 1964 aparece como matéria de constantes inquietações. Em 2008, debates realizados na Universidade de São Paulo e que depois deram origem ao livro $O$ que resta da ditadura: a exceção brasileira, organizado por Vladimir Safatle e Edson Teles (2010), traziam a difícil tarefa de falar do passado recente e sua capacidade de não passar. Naquele momento, consideravam que incidia sobre a sociedade

\footnotetext{
${ }^{3}$ São lapidares as reflexões de Hans Ulrich Gumbrecht sobre o pós-Segunda Guerra Mundial, questões que exploram as dificuldades em lidar com o passado e a memória dos horrores da guerra e do nazismo que insistem em não passar. O teórico alemão questiona se esse é um problema de sua geração ou um problema geral com que se defrontam todas as culturas e épocas que não conseguem deixar o seu passado para trás. Cf. GUMBRECHT, 2014.
} 
brasileira certo "astigmatismo histórico" e que a memória dos tempos da ditadura encontravase cada vez mais dispersa ${ }^{4}$ como resultado de múltiplas estratégias que visavam à produção do esquecimento, como se nunca houvesse feito vítimas ou causado sérias consequências. Como fantasma que ainda assombra e contamina o presente, as questões debatidas giravam em torno da "maneira insidiosa que a ditadura brasileira encontrou de não passar, de permanecer em nossa estrutura jurídica, em nossas práticas políticas, em nossa violência cotidiana, em nossos traumas sociais que se fazem sentir mesmo depois de reconciliações extorquidas" (TELLES; SAFATLE, 2010, p.9).

A constatação de diferentes pesquisadores era a de que a violência da ditadura, longe de desaparecer, resultou disseminada na sociedade, em especial, quando se considera a cultura da impunidade onde "torturadores nunca foram julgados, onde não houve justiça de transição, onde o Exército não fez um mea culpa de seus pendores golpistas" (TELLES; SAFATLE, 2010, p.10) e os oficiais na ativa e na reserva continuaram elogiando e comemorando os seus feitos. Inúmeros são os legados políticos e sociais desse período que insistem em permanecer, pois conservam as práticas violentas e, ao mesmo tempo, articulam formas de ressignificar o passado e transformar a memória do que passou em algo distante como se a sociedade não houvesse "sequer participado" (REIS FILHO, 2001, p. 136).

Em 2010, reportagens publicadas na Folha de S. Paulo apontaram que 12 colégios militares do país adotaram livros didáticos de história que não faziam referência às práticas de tortura, desaparecimentos e mortes do período da ditadura. As escolas, que poderiam utilizar livros gratuitos distribuídos pelo Ministério da Educação, optaram na disciplina de história pela obra editada pela Bibliex (Biblioteca do Exército). O livro didático História do Brasil Império e República mostrava a perspectiva de que "o golpe ocorrido em 1964 foi uma revolução democrática; a censura à imprensa, necessária para o progresso; e as cassações políticas, uma resposta à intransigência da oposição". Trazia ainda a versão de que "Goulart cooperava com os interesses do Partido Comunista, que já havia se infiltrado na Igreja Católica e nas universidades" e as Forças Armadas, por seu "espírito democrático", constituíam maior resistência à subversão comunista da luta armada. No caderno de exercícios, em questão sobre o objetivo da tomada de poder pelos militares, a resposta tida como correta era "combater a inflação, a corrupção e a comunização do país". Quanto às ações da esquerda, a narrativa enfatizava que "os grupos subversivos, além de perturbar a

\footnotetext{
${ }^{4} \mathrm{O}$ escritor Ignácio de Loyola Brandão queixa-se de que, em conversas com estudantes em eventos literários, a noção da ditadura aparece cada vez mais distante: "Você fala do regime militar brasileiro e parece que está tratando da Revolução Francesa, do Iluminismo, da Revolução Americana” (BRANDÃO, 2001, p.40).
} 
ordem pública, vitimou numerosas pessoas, que perderam a vida em assaltos a bancos, ataques a quartéis e postos policiais e sequestros" (PINHO, 2010).

O jornalista Helio Schwarsman (2010) diz que, mesmo compreendendo a existência de diferentes interpretações e concepções na historiografia, a omissão e a falsificação do passado presentes no livro adotado pelos colégios militares poderia ser considerado um crime de "lesahistoriografia", pois despreza a existência de documentos e pesquisas historiográficas sobre o período e que se opõem substancialmente aos argumentos do livro da Bibliex. O coronel Silva Alvim, na época comandante do colégio militar de Brasília, alegou que a linha didáticopedagógica da obra, adotada desde 1998, atendia de forma adequada às necessidades do ensino de história.

Questões que informam intensas disputas pelo passado, pela memória da ditadura. Aspectos que implicam desafios que dizem respeito às relações entre memória e história, às disputas pelo vivido, pela verdade, seus sentidos e significados. Dizem respeito aos usos públicos e políticos do passado, mas também ao ensino de história e, de maneira lapidar, à importância do diálogo entre os saberes históricos, acadêmicos e escolares.

Para Mateus Henrique de Faria Pereira (2015), desde 1964 diversas batalhas de memórias foram travadas na sociedade acerca da ditatura civil-militar. Entretanto, entraram em latência e emergiram de diferentes formas nos últimos anos, em particular entre 2012 e 2014, período de atuação da Comissão Nacional da Verdade. ${ }^{5}$ Se durante muito tempo, como salientam Safatle e Teles (2010), bem como Selligman-Silva (2012), a tendência predominante na sociedade brasileira era a dos que preferiam "virar a página" e enterrar a memória do período, concordamos com Pereira $(2015$, p.877) na percepção de que a partir da criação da Comissão Nacional da Verdade, houve intensificação nas guerras de memórias que ganharam ampla visibilidade, com destaque para a internet, com forte presença de textos e imagens que circularam nas redes de maneira recorrente e que, para fazer "reprimir, silenciar,

\footnotetext{
${ }^{5}$ Sua criação foi motivada a partir de intensos debates que se articularam na sociedade brasileira. A primeira iniciativa oficial para o esclarecimento das mortes e desaparecimentos ocorridos durante a ditadura civil-militar de 1964 ocorreu no ano de 1995 com a criação da Comissão Especial sobre Mortos e Desaparecidos Políticos. Em 2002, complementaram-se as políticas de memória e reparação com o estabelecimento da Comissão de Anistia. Segundo Carolina Bauer, no Brasil, a primeira década dos anos 2000 foi de intenso debate sobre a abertura dos arquivos da repressão, a possível anulação da Lei de Anistia, entre outras medidas vinculadas ao passado recente. Em 2008, durante a XI Conferência Nacional de Direitos Humanos, iniciou-se o debate sobre a criação de uma comissão da verdade. Em 2010, o projeto de lei de criação da Comissão Nacional da Verdade foi encaminhado pelo então presidente Luiz Inácio Lula da Silva ao Congresso Nacional. Em 18 de novembro de 2011, o governo sancionou a LEI n.12.528 que criava, então, a comissão que teria por finalidade esclarecer as violações de direitos humanos cometidas pelo Estado brasileiro no período de 1946 a 1988. Cf. BAUER, 2017. Entre os historiadores, a autora aponta que disputas questionavam inclusive a presença ou não de historiadores no corpo principal dos trabalhos da comissão. Sobre a lei, consultar:
} https://www.planalto.gov.br/ccivil_03/_ato2011-2014/2011/lei/112528. 
falsear ou esquecer", passaram a contestar a realidade da ditadura a partir de discursos negacionistas e/ou revisionistas. ${ }^{6}$ Práticas e discursos alimentados, em grande medida, pela impunidade, pela ausência de justiça que foi estimulada pela permanência da Lei da Anistia de 1979, pelo não reconhecimento da culpa e ausência de arrependimento ou remorso "por parte dos algozes diretos e indiretos e dos apoiadores de ontem e de hoje" (PEREIRA, 2015, p. 865).

Se, por um lado, a Comissão Nacional da Verdade que procurou investigar, sem poder de punição, as violações de direitos humanos cometidas pelo Estado, foi comemorada por alguns setores da sociedade e contribuiu para reforçar a importância das funções sociais do historiador, além do processo de visibilidade dos testemunhos e dos debates públicos suscitados sobre o passado autoritário recente, por outro, como já mencionamos, houve considerável disseminação de discursos e representações negacionistas da ditadura civilmilitar que se caracterizam, não necessariamente, pela negação da realidade, mas, sobretudo, pela busca de justificativas que legitimassem o terrorismo de Estado (BAUER, 2017).

Muitos ex-agentes dos aparatos repressivos e de informações e militares da reserva, ao testemunharem em audiências na CNV [Comissão Nacional da Verdade] ou ao se manifestarem no debate público, narraram determinadas construções sobre o passado que evidenciam essas características, como, por exemplo, a necessidade de um golpe e de uma ditadura frente ao perigo comunista ou da subversão, ou a existência da tortura como resultado de 'excessos' cometidos individualmente, nunca de forma institucional (BAUER, 2017, p.42).

Extrapolando os âmbitos militares, no período da Comissão Nacional da Verdade (2012-2014), outras redes, sociabilidades e "comunidades de memória" passaram a se organizar, de forma mais ou menos espontânea, a partir do uso da internet e de outras tecnologias digitais com a finalidade de falsificar e distorcer as evidências e os fatos historicamente comprovados. Nessas guerras de memórias, o passado falsificado é transmitido e difundido em uma versão idealizada e que guarda forte relação de fidelidade também com os antepassados, pois serve para "justificar, autojustificar e também se autoabsolver dos erros e crimes imputados à comunidade” (PEREIRA, 2015, p.88-884).

Trata-se de agentes civis e militares que, para Caroline ${ }^{7}$ (2017, p.42), como constituintes dessas "comunidades de memória", constroem coesão e unidade nas representações do passado recente, o que se alarga se pensarmos na transmissão desses

\footnotetext{
${ }^{6}$ Sobre os termos negacionismo e revisionismo, cf. PEREIRA, 2015; TRAVERSO, 2012.

${ }^{7}$ Optamos por mencionar, no corpo do texto, o primeiro nome das autoras como forma de visibilizar a produção acadêmica e intelectual das mulheres, cientes de que muitas vezes o destaque para o sobrenome induz relacionar à autoria masculina.
} 
pensamentos a partir do ensino de história, como o que parece ocorrer dentro dos colégios militares já de longa data. Imaginem quantos estudantes foram formados e orientados dentro dessas convicções.

Convicções que ganharam ainda mais força, em especial, a partir do golpe/impeachment de 2016 - em que a presidenta Dilma Rousseff foi destituída do cargo para o qual foi eleita em 2014 - e das eleições presidenciais de 2018, momentos também significativos em que a ditadura ganhou ainda mais centralidade em determinados discursos ${ }^{8}$ que passaram, não só a justificar a ditadura, como também a atacar os historiadores. É cada vez mais comum a presença de apoiadores que pedem em manifestações públicas a intervenção militar e a volta da ditadura, muitos a partir de conhecimento questionável sobre o período, outros bem cientes do que querem.

Segundo Caroline (2017, p. 199), durante os trabalhos da comissão, muitas manifestações de descontentamento ganharam visibilidade, em especial, no período que antecedeu a entrega do relatório final. Inconformados, representantes de grupos militares criticaram o relatório "assinado por advogados, juristas e professores universitários" e atribuíram a ele o desejo de vingança, além de associarem a comissão à esquerda brasileira. Os setores militares também se mostraram indignados e surpresos com a lista do relatório que trazia 377 nomes de agentes do Estado - dentre os quais, 190 ainda estavam vivos à época acusados e reconhecidos pela justiça brasileira pelas graves violações de direitos humanos.

Para além dos embates nos momentos finais da Comissão Nacional da Verdade, todo o processo foi marcado por fortes conflitos, como a acentuada indisposição, por parte de setores militares, em cooperar com as investigações. Caroline (2017, p.199-200) aponta as tensões que envolveram a relação da comissão com o Ministério da Defesa e com os comandantes das Forças Armadas em diversos momentos, além das represálias aos militares que se prontificaram a colaborar com os trabalhos da comissão. Caso notório, levantado pela autora, foi o do tenente-coronel Paulo Malhães, encontrado morto com sinais de asfixia um mês após prestar depoimento à comissão, momento em que se confirmou a existência de centros clandestinos de detenção e das práticas de torturas, mortes e desaparecimentos.

A Comissão Nacional da Verdade possibilitou que memórias antes circunscritas aos âmbitos familiares e de amigos fossem compartilhadas ganhando espaço e visibilidade pelos

\footnotetext{
${ }^{8}$ Desde 2010, sobretudo, por ocasião da campanha eleitoral presidencial, a figura de Dilma Rousseff, passou a ser alvo de inúmeras críticas relacionadas à sua atuação durante o período da ditadura civil-militar. Várias imagens, memes e discursos acionaram esse passado, a partir do qual foi acusada de terrorista, assaltante e assassina. Essa estratégia política, realizada no escopo das fake news, com o propósito deliberado de desqualificar a candidata no jogo eleitoral, colocou a ditadura brasileira também em evidência.
} 
debates fomentados na esfera pública. Mais do que as implicações políticas e sociais na vida dos envolvidos nos crimes cometidos pelo Estado, importante destacar os afetos e traumas enfrentados pelos perseguidos políticos e ex-presos e seus entes, além dos familiares de mortos e desaparecidos. Para muitos, além da insatisfação com os resultados da comissão, o processo significou a reatualização dos traumas experimentados e as dificuldades psíquicas que isso acarreta (BAUER, 2017, p.200).

A partir das pesquisas de Caroline e Pereira, podemos dimensionar a repercussão dos trabalhos da Comissão Nacional da Verdade na sociedade brasileira. Enquanto Caroline procurou analisar, dentre outros aspectos, as tensões e as disputas que ocorreram dentro dos trabalhos da comissão, as dificuldades nas investigações, os embates com os militares, Pereira explorou, para além do âmbito institucional da comissão, os impactos dela na sociedade a partir de ataques negacionistas e/ou revisionistas disseminados por meio da internet e das tecnologias digitais, indagando, inclusive, a sua relação com a aparição de uma "nova direita" no Brasil. O pesquisador destaca que essa "comunidade de memória" atuante na falsificação do passado da ditadura brasileira é formada por diferentes atores e colaboradores, desde militares da ativa e da reserva, jornalistas, setores da direita, até mesmo historiadores, dentre outros, e que se juntam a grupos que constituem porta-vozes de certos fundamentalismos crescentes no país desde 2003 (PEREIRA, 2015, p. 883)

A impunidade em relação aos crimes praticados pelo Estado durante o período de 1964-1985 constitui, para Pereira (2015, p.884), a fórmula que faz com que essa comunidade se perceba capaz de, no presente, justificar suas práticas, discursos e ideologias e, desse modo, "persista, cresça e se transforme e, sobretudo, que não sinta ou manifeste remorso ou culpa e, por consequência, não aceite nem reconheça qualquer tipo de erro". Se dentro dos colégios, quartéis e clubes militares, essa história falsificada e dissimulada se fez presente, seja nos livros didáticos como também nas festividades - lembrando que até 2012 havia dentro dos quartéis comemorações pela "Revolução de 1964", somente sendo proibidas no governo de Dilma Rousseff (FICO, 2012), ainda que não tenha sido devidamente cumprida a proibição e que ela passou a ser novamente incentivada na atualidade -, a Comissão Nacional da Verdade pode ter contribuído de forma significativa para despertar novos rancores e ressentimentos.

Sentimentos que, articulados à impunidade, estimularam o desejo, por parte dessa comunidade, de ampliar a audiência para as narrativas negacionistas que já faziam parte do seu cotidiano: na medida em que não houve punição, nem ao final da ditadura civil-militar e nem com a Comissão Nacional da Verdade, esse grupo passa a se perceber com "grande autonomia narrativa em relação à comunidade maior, no caso, a Nação" (PEREIRA, 2015, 
p.884). Para Pereira (2015), essa guerra de memória, estimulada por sentimentos e componentes de irracionalidade, persistirá enquanto os atos e os agentes de crimes realizados no passado não sofrerem nenhuma punição.

Carlos Fico (2012) também concorda que o reconhecimento da impunidade assinala a nossa transição incompleta e inconclusa que diz muito das maneiras como a sociedade brasileira construiu suas memórias desse período. Além da ausência de punição, os processos de silenciamento promovidos pelo Estado e pela sociedade constituem, para Caroline (2017), formas de atualizar o passado no presente, fazendo irromper, na democracia, os traumas da ditadura.

Se, por um lado, há na sociedade brasileira uma espécie de "mal de Alzheimer nacional", retendo aqui a literatura na forte expressão de Bernardo Kucinski (2016, p.15), por outro, temos os usos inadequados e indecentes do passado que, além de negar as narrativas e evidências da história na tentativa de construir formas mais "adequadas" a determinados interesses, despertam o desejo pela intervenção militar e a volta da ditadura. Frente a tais descompassos, qual o papel de historiadoras e historiadores? Qual o papel do ensino de história?

Desafios éticos e políticos que dizem respeito, sobretudo, à elaboração do passado, à memória e ao esquecimento, seu par inseparável, e aos usos públicos e políticos do passado. O enfrentamento dessas questões exige reflexões de ordem epistemológica, ética e política. Passados recentes dizem respeito a memórias em conflito e, muitas vezes, colocam em pauta os limites do conhecimento e a tensão entre subjetividade e objetividade. A memória da ditadura tem sido cada vez mais objeto de "disputa, de conflito, de interpretação, de revisão" (PEREIRA, 2015, p.891).

Ao refletir sobre verdade do passado, Jeanne Marie Gagnebin (2006), em diálogo com Walter Benjamin, diz da impossibilidade de transparência e/ou correspondência entre o discurso científico e os fatos históricos. Articular "historicamente o passado não significa conhecê-lo 'tal como ele propriamente foi'. Significa apoderar-se de uma lembrança tal como ela cintila num instante de perigo" (BENJAMIN, 2012, p.11). Significa que nós articulamos o passado, não o descrevemos de maneira exata e exaustiva. E se os documentos dos historiadores não podem "dizer tudo", se o passado não existe na sua forma pura nas fontes, "se evidência e história não existem ou não se evidenciam por si mesmas, mas aguardam quem as construa e as informe" (CAMILOTTI; NAXARA, 2009, p.42), se uma fonte "não pode nos dizer nada daquilo que cabe a nós dizer" (KOSELLECK, 2006, p.188), fato é que não existe uma realidade pronta aguardando o historiador. Se, em termos epistemológicos, a 
busca da história não pode ser pelo estabelecimento de uma verdade unívoca e indiscutível, se é da natureza da história a sua necessidade contínua de reescrita, o que não indica fragilidade dentro de critérios regulados metodicamente, se não há discurso legítimo sobre o passado, se a escrita da história não pode perder de vista o seu caráter incompleto e fragmentário, como lidar com negacionismos que colocam em suspenso a nossa prática, o nosso ofício e as evidências da história? A tensão que se coloca toca de perto o fazer da história e a complexidade de sua demanda, em especial, pela acolhida de vestígios materiais do passado que tem por foco temas sensíveis que dizem respeito a enfrentamentos de traumas e eventoslimite e toda a carga humana que carregam. O que assinala a responsabilidade ética da história e do historiador, mais do que a "problemática da adequação (pretensamente científica) entre 'palavras' e 'fatos"' (GAGNEBIN, 2006, p.42).

Safatle e Teles (2010) e Selligman-Silva (2012) concordam que a violência da ditadura não se mede pela contagem dos "mortos deixados para trás", mas através das suas marcas no presente e que se projetam para o futuro. Nessa chave interpretativa, a ditadura no Brasil teria sido mais violenta que as outras vivenciadas na América Latina, justamente por sua capacidade de não passar, por ir "muito além da data oficial de seu fim" (SELLIGMANSILVA, 2012, p.64).

Interessantes as questões apontadas por Denise Rollemberg (2006) em texto de título provocativo "Esquecimento das memórias" - que, em parte, desconstrói, questiona e problematiza o discurso que durante muito tempo foi fortemente difundido de que a esquerda teria vencido a luta pela memória histórica do período, ou seja, se os militares venceram a guerra contra as organizações de esquerda, perderam na batalha de memórias.

Após o fim controlado da ditadura, surgiram inúmeros relatos que buscavam contar o passado. Denise (2006) aponta que, apesar da grande quantidade de narrativas e de sua pluralidade, uma delas alcançou unanimidade na opinião pública: $O$ que é isso companheiro, de Fernando Gabeira publicada em 1979. Para Daniel Aarão Reis Filho (1997, p.33), a grande receptividade estaria ligada à mensagem de conciliação que a narrativa de Gabeira trazia. A preocupação do historiador diz respeito à reflexão sobre a responsabilidade individual e coletiva que se manifesta também nas narrativas e manifestações artísticas. Em larga medida, o controle sobre o futuro passa também pela gestão do passado, pela autoridade e domínio exercido por aqueles que imprimem na memória coletiva a sua específica visão dos acontecimentos. Nesse sentido, parecia "bem mais pertinente uma recuperação do passado recente que não colocasse o dedo na ferida, não abordasse as relações de identidade ou apoio 
ou omissão ou colaboração de parte expressiva da sociedade com o regime" (ROLLEMBERG, 2006, p.85).

A preocupação de Reis Filho e de Denise trazem o questionamento de determinadas versões do passado que, longe de indagar os conflitos e as tensões numa postura crítica, optam por abrir caminho para a conciliação acrítica ou limitadora que, distante de lembrar e elaborar o passado, fazem mais silenciar, por isso a desconfiança nas versões em que se pode reconstruir o passado sem se atormentar com ele. Fenômenos que longe de fazer conhecer a história, a torna ainda mais desconhecida. Como nos lembra Andreas Huyssen (2014, p.158), o esquecimento precisa ser situado num campo de termos e ocorrências como "silêncio, desarticulação, evasão, apagamento, desgaste, repressão", todos os quais revelam um espectro de estratégias tão complexo quanto o da própria memória.

A aceitação dessa versão pouco abonadora, na perspectiva daquilo que Elizabeth Cancelli toma como "forma adequada de rememoração" (CANCELLI, 2012) - em que o excesso de memória longe de fazer lembrar, contribui e colabora com o esquecimento -, diz muito do abismo que se abriu entre o passado e o futuro, em especial, pela dificuldade, entre os militantes da esquerda e até mesmo entre historiadores e especialistas, de "admitir uma sociedade na qual a maior parte, oprimidos inclusive, se identificasse com valores da ditadura e não se indignasse com os crimes por ela cometidos" (ROLLEMBERG, 2006, p.85). Chama a atenção na leitura de Reis Filho $(1997 ; 2001)$ o incômodo de refletir sobre a permanência da ditadura durante tanto tempo e sua relação com a sociedade brasileira. Denise também destaca essa presença nas muitas narrativas testemunhais que apareceram a partir dos final dos anos 70 deixa a fragilidade com que as relações da sociedade com o regime eram tratadas: "Inseridos numa determinada cultura política, era difícil ver a aceitação o regime, compreendê-lo como produto da sociedade, que não lhe era estranho, que havia ali laços de identidade" (ROLLEMBERG, 2006, p.88).

Denise (2006, p. 88) não deixa de advertir sobre os "esquecimentos da memória", daquela memória "coesionadora" ${ }^{9}$ que manteve nas sombras a cumplicidade, a omissão, os compromissos, a colaboração e o apoio. Esquecimento que, para Huyssen (2014, p.155), longe de ser falha da memória, seu complemento inevitável ou deficiência, constitui

\footnotetext{
${ }^{9}$ Podemos lembrar também a reflexão de Carlos Fico sobre as circunstâncias que levaram à constituição de uma memória relativamente dominante sobre a ditadura brasileira, marcada pela perspectiva do confronto entre a luta armada e a repressão. Atento ao fenômeno da memória e suas lutas plurais pelo estabelecimento da verdade, o que o autor procura destacar é a problemática redução da história do Brasil do período de 1964 e 1985 à "história da repressão e dos reprimidos, do confronto entre luta armada e repressão", o que retira e desarma a complexidade política da história e do período, além de impedir o reconhecimento de tensas zonas cinzentas na sociedade como o amplo apoio de parcela significativa da sociedade. Cf. FICO, 2012.
} 
fenômeno de múltiplas camadas. A fórmula conciliação e formas adequadas de rememoração diz muito desse passado:

A luta armada e a sociedade, dois mundo paralelos, desconhecidos um do outro; a vanguarda querendo transformar o que desconhecia, indiferente aos valores, às aspirações que moviam os indiferentes na direção oposta [...]. Passados os anos, dois mundos ainda paralelos. De um lado, a ditadura e os crimes. De outro, a sociedade que os desconhecia. Essa dualidade tem sido um eixo estrutural das memórias, da construção da memória coletiva da luta armada e da ditadura. (ROLLEMBERG, 2006, p.88-89)

É desse lugar, dois mundos paralelos e desconhecidos, que se problematiza a exigência acrítica de memória e, muitas vezes, o descaso com o esquecimento, afinal, como provoca Huyssen (2014, p.160), a "política da memória não pode prescindir do esquecimento". Dois mundos paralelos e desconhecidos que, para Denise, sinalizam a incompreensão do passado. A fragilidade com que as relações da sociedade com a ditadura ganharam (ou não ganharam) forma nos discursos, na vida pública, nos trabalhos acadêmicos e nas narrativas testemunhais, fez com que não se instalasse a inscrição, a memória, mas o esquecimento das memórias. Assim, "a indiferença, a omissão, a cumplicidade e tudo mais que há bem antes de se chegar ao apoio irrestrito e que se traduz, depois, em 'nós não sabíamos', 'nós nada víamos', devem ser analisados" (ROLLEMBERG, 2006, p.99). Inquietação que nos remete, acompanhando o escritor Ignácio de Loyola Brandão (1995, não p.), para a face perversa e hedionda, a parte "silenciosa e tenebrosa que existe em todo mundo. Os que nada veem, nada ouvem, nada fazem, fecham portas e janelas - mas olham pelas frestas - e se omitem". A existência de pessoas comuns que, pela inação, colaboram com o horror. Banalidade do mal que, para Hannah Arendt, desafia as palavras e os pensamentos (ARENDT, 1999).

Relevantes são as reflexões de Beatriz Sarlo (2007, p.20) que, embora, tenha uma abordagem mais específica sobre a Argentina pós ditadura, não deixe de contribuir para o debate a respeito do Brasil e de outros países da América Latina que viveram situação correlata. Preocupada com a emergência de uma guinada subjetiva nos anos 1980, Beatriz destaca os riscos de se transformar a memória em história. Para a autora, o campo da memória é um campo de conflitos "entre os que mantêm a lembrança dos crimes de Estado e os que propõem passar a outra etapa". É também um campo de conflitos para:

os que afirmam ser o terrorismo de Estado um capítulo que deve permanecer juridicamente aberto, e que o que aconteceu durante a ditadura militar deve ser ensinado, divulgado, discutido, a começar pela escola. É um campo de conflitos também para os que sustentam que o "nunca mais" não é uma conclusão que deixa para trás o passado, mas uma decisão de evitar, relembrando-as, as repetições (SARLO, 2007, 20) 
Preocupada com a construção de certezas e verdades apresentadas como irrefutáveis e, sem esvaziar, o papel fundamental dos relatos testemunhais, enfatiza os usos políticos dos saberes da história e da memória. Mesmo que os atos de memória e o testemunho sejam importantes sob vários aspectos (jurídico, político e ético), o excesso de memória, uma vez cristalizado, pode também fragilizar o conhecimento crítico. Ao afirmar os limites das narrativas de testemunho, busca garantir espaço onde a complexidade da experiência humana tenha lugar garantido. Contra o excesso de memória que nem sempre liberta e pode conduzir a novos conflitos, reconhece que é mais importante "entender do que lembrar, embora para entender também seja preciso lembrar" (SARLO, 2007, p.22).

A preocupação de Beatriz (2007) toca de perto a fragilidade de determinadas reconstituições e narrativas que atendem facilmente aos apelos mercadológicos constituindo formas adequadas de rememoração que, muitas vezes, eliminam a complexidade e a descontinuidade oferecendo ao público um sentido explicativo que unifica os fragmentos do passado. O que a historiografia não pode propor-se a fazer, pois opera no interior de regras e métodos que supervisionam a reconstrução do passado sem negligenciar a sua condição multiforme e a pluralidade da experiência humana e histórica e, sobretudo, com a consciência de que o passado escapa a toda forma de captura integral.

A incompreensão e o desconhecimento do passado persistem se pensarmos que "em comparação com jovens argentinos e uruguaios, os brasileiros são os que têm menos interesse no passado militar e os que têm menores rejeições a "opções militaristas"” (DUARTE; CERRI apud PEREIRA, 2015, p.887). Outra pesquisa, realizada em 2010 sobre o "Golpe de 1964 e a Ditadura Militar", constata que há "elevado índice de pessoas que não souberam responder às questões, demonstrando total desconhecimento (ou esquecimento) dos eventos e processos relacionados ao golpe de 1964 e ao regime militar dele decorrente" (CERQUEIRA; MOTTA apud PEREIRA, 2015, p.888).

Em importante reflexão, Márcio Seligmann-Silva (2014, p.30), aponta que foram muitas as formas e estratégias para se constituir a não inscrição do passado da ditadura civilmilitar no Brasil. Entre nós, não se desenvolveu e "provavelmente não se desenvolverá", uma cultura da memória com relação à ditadura, assim como não se desenvolveu "uma cultura da memória em relação ao genocídio indígena, ao de africanos e de afrodescendentes, à escravidão, à ditadura Vargas e à história das lutas no campo e nas cidades no Brasil". O que vemos é a repetição e reprodução dos traços de uma cultura autoritária na sua dimensão violenta, hierárquica e desigual. 
Essa ausência é, para o autor, resultado da não inscrição da memória no espaço público. O conhecimento da violência do período da ditadura teria ficado restrito e somente familiares e pessoas próximas às vítimas, além dos próprios sobreviventes, se interessaram por esse tema e "investiram na sua memória, na reconstrução da verdade e na busca da justiça” (SELIGMANN-SILVA, 2014, p.31). Para Mateus Pereira:

Os conflitos de memória e o combate à negação e a certos revisionismos têm auxiliado a revelar ou a descobrir as marcas, as cicatrizes do passadopresente, criando uma atmosfera em que se torna possível inscrever de forma sutil essas marcas na memória pública de toda a nação e não só na de grupos particulares (PEREIRA, 2015, p.889).

Se Seligmann-Silva constata uma não inscrição ou inscrição precária e tênue da violência no Brasil, Pereira (2015) sinaliza que a Comissão Nacional da Verdade, mesmo dentro de suas limitações, criou perspectivas para uma possível inscrição, ainda que frágil, de uma memória pública da ditadura civil-militar. Como elementos importantes para o entendimento da guerra de memória que, a partir da comissão, se intensifica, os negacionismos e/ou revisionismos são compreendidos dentro de uma chave interpretativa que vê na intensificação dessas práticas, uma reação simbólica no sentido de impedir e reprimir a visibilidade e a fixação dessa memória no espaço público.

Nesse sentido, a reação contra a constituição de uma possível memória pública intensifica-se com a comissão da verdade e a aceitação da negação e/ou do revisionismo, por parte de diferentes públicos, passaram a alimentar ainda mais a ausência de arrependimento, remorso, culpa ou reconhecimento dos erros cometidos. Pereira (2015, p.893) constata que alguns "militantes ativos" nas práticas de falsificação do passado são ligados direta ou indiretamente à ditadura, além da presença de pessoas que foram ligadas à estrutura repressiva. Assim, longe de "demarcar um novo tempo" de "reconciliação" - como afirmou a presidente Dilma Rousseff no discurso otimista de encerramento dos trabalhos da comissão e entrega do relatório final que ocorreu no dia 10 de dezembro de 2014 -, a comissão pode ter despertado ainda mais ódios e ressentimentos (BAUER, 2017, p.194) e os conflitos de memória ficaram ainda mais acirrados.

Conflitos e disputas que podem provocar medos, ressentimentos, indiferenças, humilhações e até mesmo o sentimento de vingança. Como demonstrou Caroline, grandes desafios e tensões permearam os trabalhos de investigações da comissão, levando para o espaço público, com cobertura midiática, os debates sobre nosso recente passado autoritário, momento que abria a possibilidade para que a sociedade começasse a debater socialmente os significados e os sentidos da ditadura. Como atesta Pereira, o negacionismo e/ou revisionismo 
histórico sobre a ditadura civil-militar intensificou-se com a comissão e, podemos dizer que, longe de arrefecer os ânimos, expandiu-se. Caberia indagar, qual o papel desempenhado pela Comissão Nacional da Verdade, não apenas em relação ao desprezo pela história e os historiadores, mas também em relação ao crescente autoritarismo, intolerância e descaso pela intelectualidade e pela ciência?

As disputas pelo passado e pelo vivido não cessam de ganhar novas dimensões e contornos. Quando deputado federal, Jair Bolsonaro escandalizou parte da sociedade na votação que destituiu a presidente Dilma Rousseff de seu cargo. ${ }^{10}$ Sua declaração, desrespeitosa em relação aos Direitos Humanos e à democracia, presta homenagem a personagem da história da ditadura reconhecido pela justiça brasileira como agente da tortura. Vem carregada de ressentimentos a partir de frase bastante significativa: "Perderam em 64 . Perderam em 2016". Diz muito de uma história que não passa, de ódios e rancores constantemente alimentados e realimentados.

Em outro momento de exposição em rede nacional, durante a campanha de 2018, ganha destaque outra afirmação não menos problemática. Ao ser confrontado com a informação de que a historiografia brasileira registra a ocorrência do golpe de Estado em 1964, respondeu: “deixa os historiadores para lá". ${ }^{11}$ Para além da desqualificação da história e dos historiadores, mostra o desprezo pelo fazer historiográfico como estratégia política e desejável política de governo que não esconde a ambição de validar outras narrativas e outras "histórias" que possam sustentar um passado que lhe seja mais conveniente, colocando em descrédito as contribuições da historiografia para o debate público sobre o passado brasileiro. Sinaliza ainda o quanto a história e os historiadores parecem incomodar...

É oportuna aqui a perspectiva de Antoine Prost (2012) para quem a história, antes de ser uma atividade intelectual ou disciplina científica, constitui uma prática social que é assumida por profissionais que se reconhecem e são reconhecidos como historiadores, além de ser aceita como história por diferentes públicos. História que, para Márcia Regina Capelari Naxara (2010, p.219), desperta nos indivíduos a curiosidade em relação aos acontecimentos do passado, o que traduz sentimentos de pertencimento e colabora para o "situar-se no presente, no contemporâneo, numa relação de continuidade e compartilhamento com os feitos e fatos do passado". Vista e avaliada como "importante patrimônio do passado", a história é

\footnotetext{
10 "Perderam em 64. Perderam agora em 2016. Pela família e pela inocência das crianças em sala de aula, que o PT nunca teve. Contra o comunismo, pela nossa liberdade, contra o foro de São Paulo, pela memória do coronel Carlos Alberto Brilhante Ustra, o pavor de Dilma Rousseff'. (Folha de S. Paulo, 20/04/2016)

${ }^{11}$ Disponível em: https://g1.globo.com/jornal-nacional/noticia/2018/08/28/jair-bolsonaro-psl-e-entrevistado-nojornal-nacional.ghtml.
} 
vivida por diferentes grupos como depositária de importante papel na transmissão de saberes entre gerações.

Transmissão de saberes, os do passado e da história, que se entrelaçam e permeiam a sociedade de maneira conflituosa. Cultura histórica (LE GOFF, 1990, p.48) como conhecimento que nem sempre está relacionado diretamente ao campo da historiografia e à intervenção dos historiadores e historiadoras. A sociedade é atravessada por diferentes concepções de história e de memória e que podem constituir-se a partir de diferentes espaços e lugares, o que inclui as novas tecnologias de informação e comunicação. São grandes os avanços tecnológicos que invadem a esfera social e não se trata de mera transformação técnica, pois implica também mudanças nas formas como as pessoas comunicam-se e experimentam a realidade. Novas mídias e configurações em compartilhamentos e produção de saberes que, muitas vezes, colocam em questionamento o próprio conhecimento crítico da história.

Dialogando com as mudanças em curso, Bruno Leal (2014) destaca a importância da dimensão pública da história e sua escrita. Diante dos problemas relacionados aos negacionismos e/ou revisionismos, o campo da História Pública - entendendo a internet como importante plataforma de divulgação de história - pode possibilitar às historiadoras e historiadores profissionais, de forma crítica, participativa e emancipatória, uma maior mobilização e engajamento de diferentes públicos não especializados com o conhecimento histórico.

Vivemos tempos de incertezas em que a escrita e o ensino de história são cada vez mais questionados e até mesmo criminalizados no que se refere ao caráter político de nosso ofício. Historiadores e historiadoras vivem sob a mira de grupos e movimentos que procuram questionar o caráter ético e político da educação. Aspectos que também indiciam a presença de um passado vivo. Dizem respeito a temas sensíveis (SEFFNER, PEREIRA, 2018) que se relacionam com as memórias em disputa, o que nos traz uma espécie de latência da memória que envolve uma tensão: a estranha presença de um passado que não passou. Nesse caso, um passado autoritário que vê na figura dos historiadores os inimigos a combater.

Nas reflexões de Gumbrecht (2014), chama a atenção a metáfora do passageiro clandestino. Diz respeito às condições de sensibilidade do passado, à incapacidade de encontrar uma relação estável e segura com o vivido, daquilo que pode tornar o passado intuitivamente presente e que implica tensões e angústias:

Numa situação de latência, sempre há um passageiro clandestino, sentimos que existe alguma coisa (ou alguém) que não conseguimos agarrar ou tocar 
[...]. É impossível dizermos com precisão de onde nos vem a certeza dessa presença, tampouco sabemos afirmar exatamente onde está agora aquilo que é latente [...]. E, porque não conhecemos a identidade do objeto ou da pessoa latente, nada nos garante que reconheceríamos essa entidade se alguma vez viesse a revelar-se diante de nós [...], aquilo que está latente sofre transformações durante o tempo em que permanece oculto. Um passageiro clandestino envelhece, por exemplo. (GUMBRECHT, 2014, p. 40)

O passado que insiste, persiste e sobrevive no presente nunca é o mesmo - o que resta atualiza-se no presente como na metáfora do passageiro clandestino. A ditadura civil-militar de 1964, como passado vivo, constitui um paradoxo temporal (SEFFNER, PEREIRA, 2018): não pertence ao passado, invade e perturba o presente. O passado vivo estende-se ao presente e habita a memória, transformando-se e constituindo experiências.

Para além das possíveis críticas ao processo e aos trabalhos da comissão da verdade, muitos pesquisadores animaram-se com as recomendações do relatório que mostrou a preocupação com o ensino de história, a transmissão de memórias e saberes e a promoção dos direitos humanos nas escolas (BAUER, 2017, p.212). A comissão teve também a oportunidade de refutar versões questionáveis sobre a ditadura civil-militar, que representam culturas históricas baseadas em argumentações negacionistas e/ou revisionistas.

O passado recente é inconcluso, aberto. Envolve temas sensíveis e a disputa por versões e imagens do vivido. Questões ainda de difícil acolhimento na esfera da reflexão e do pensamento. Nilton Mullet Pereira e Fernando Seffner (2018, p. 17) enfatizam o caráter ético e político da história e do seu ensino como campo fundamental para a educação em direitos humanos, o que não implica "atitudes desinteressadas, mas voltadas ao futuro - um futuro de tolerância, de reconciliação com a justiça e com os direitos". Significa processos de intervenção da História em seus vínculos éticos e estéticos. Formas a partir das quais o conhecimento histórico, no espaço escolar, pode contribuir para a reflexão e conhecimento ao mobilizar fatias do passado recente, ainda carregadas de sentimentos, medos, indiferenças e humilhações.

O ensino de história pode ser o lugar possível para o enfrentamento de questões difíceis. A história, como “saber e prática inseparável de discussões éticas e políticas", é lugar de refletir os conflitos e as desigualdades, de ensinar a conviver com a diversidade e a se posicionar no mundo, afinal, dentre outras possibilidades, ela "serve para produzir subjetividades humanas, para humanizar, para construir e edificar pessoas" (ALBUQUERQUE JÚNIOR, 2012, p.31).

Instigante a indagação "Como será o passado?" de Caroline Silveira Bauer. Diz muito das preocupações com o futuro da memória da ditadura civil-militar, mas também sobre o 
trabalho da história e sua reescrita incessante, sobre a memória e sua permanente negociação e transformação no presente. A pergunta de Jörn Rüsen (2014, p.101) - "Pode-se melhorar o ontem?" - igualmente instigante, traz a tarefa de interpretação do passado na possibilidade de orientar o agir e a experiência temporal. Expectativas de futuro condicionadas ao fazer e tornar melhor o passado, o que não significa falsificar os fatos, mas o entendimento dos efeitos do vivido sobre o presente e a acolhida de sentidos para as demandas do presente.

Recorremos mais uma vez a Beatriz Sarlo (2016, p.32) e à força da literatura que também pode acolher a ambivalência e a complexidade, oferecendo abertura às múltiplas dimensões da experiência, formas e sentimentos: "os textos existem" e são obstáculos contra "o convite ao esquecimento", sua possibilidade ou imposição. Teimam em "opor-se à hipocrisia de uma reconciliação amnésica" que pretende calar o que já se sabe: as áreas sombrias que, para Bernardo Kucinski (2016) em texto que mostra a procura do pai pela filha desaparecida na ditadura, trazem a insegurança do passado e sua insistência:

Também os sobreviventes daqui estão sempre a vasculhar o passado em busca daquele momento em que poderiam ter evitado a tragédia e por algum motivo falharam [...]. O 'totalitarismo institucional' exige que a culpa, alimentada pela dúvida e opacidade dos segredos, e reforçada pelo recebimento das indenizações, permaneça dentro de cada sobrevivente como drama pessoal e familiar, e não como a tragédia coletiva que foi e continua sendo, meio século depois. (KUCINSKI, 2016, p.156)

Também é bom lembrar, como alerta Huyssen (2014, p.174) que "quando certas lembranças, inclusive as "corretas"”, são sistematizadas em consenso nacional podem surgir novas ameaças à memória. E o "excesso de memória" e sua comercialização em massa, pode gerar outras formas de esquecimento: a exaustão e um "não querer saber".

\section{Referências Bibliográficas:}

ALBUQUERQUE JR, Durval Muniz. As sombras brancas: trauma, esquecimento e usos do passado. In: VARELLA, Flávia. et al. Tempo presente \& usos do passado. Rio de Janeiro: FGV, 2012.

ALBUQUERQUE JR, Durval Muniz de. Fazer defeitos nas memórias: para que servem o ensino e a escrita da história?. In: GONÇALVES, Márcia de Almeida. [et al.] (orgs). Qual o valor da história hoje? Rio de Janeiro: Editora FGV, 2012, p. 21-39.

ARENDT, Hannah. Eichmann em Jerusalém: um relato sobre a banalidade do mal. Trad. José Rubens Siqueira. São Paulo: Cia das Letras, 1999.

BENJAMIN, Walter. Sobre o conceito de história. In: $O$ anjo da história: Walter Benjamin. Organização e tradução. João Barrento. Belo Horizonte: Autêntica. 2012.

BRANDÃ̃, Ignácio de Loyola. Não Verás País Nenhum. 15ª ed. São Paulo: Global, 1988. 
BAUER, Carolina Silveira. Como será o passado?: História, Historiadores e a Comissão Nacional da Verdade. 1ed. Jundiaí, SP: Paco, 2017.

Cadernos de Literatura Brasileira: Ignácio de Loyola Brandão. n. 11/Junho. São Paulo: Instituto Moreira Sales, 2001.

CAMILOTTI, Virgínia Célia; NAXARA, Márcia R. Capelari. História e Literatura: Fontes literárias na produção historiográfica recente no Brasil. In: História: Questões e Debates. Curitiba, n. 50, p.15-49, 2009.

CANCELLI, Elizabeth. A violenta memória do esquecimento. In: Trivum. Rio de Janeiro, v. 4, n. 2, dez. 2012. Disponível em: http://pepsic.bvsalud.org/scielo.php?script=sci_arttext\&pid=S2176$48912012000200009 \& \operatorname{lng}=$ pt\&nrm=iso $>$. Acesso em 12/ dez./2013.

FALCÃO, Márcio. Bolsonaro fez apologia de crime na votação do impeachment, diz OAB. Folha de São Paulo. 20 abr. 2016. Disponível em: https://www1.folha.uol.com.br/poder/2016/04/1763027-bolsonaro-fez-apologia-ao-crime-navotacao-do-impeachment-diz-oab.shtml Acesso em: 15 jun 2018.

FICO, Carlos. Brasil: a transição inconclusa. In: ARAÚJO, Maria Paula; FICO, Carlos; GRIN, Monica (org.). Violência na história: memória, trauma e repressão. Rio de Janeiro: Ponteiro, 2012. Versão e-book.

FUKS, Julián. A resistência. São Paulo: Companhia das Letras, 2015.

GAGNEBIN, Jeanne Marie. Lembrar escrever esquecer. São Paulo: Editora 34, 2006.

GUMBRECHT, Hans Ulrich. Depois de 1945: latência como origem do presente. Trad. Ana Isabel Soares. 1ed. São Paulo: Editora Unesp, 2014.

HYUSSEN, Andreas. Cultura do passado-presente: modernismos, artes visuais, políticas da memória. Trad. Vera Ribeiro. 1ed. Rio de Janeiro: Contraponto: Museu de Arte do Rio, 2014. KOSELLECK, Reinhart. Futuro Passado: contribuição à semântica dos tempos históricos. Trad. Wilma Patrícia Maas e Carlos Almeida Pereira. Rio de Janeiro: Contraponto: PUC-Rio, 2006.

KUCINSKI, Bernardo. K. Relato de uma busca. São Paulo: Companhia das Letra, 2016.

LEAL, Bruno. Faça aqui seu login: os historiadores, os computadores e as redes sociais online. Revista História Hoje, v.3, nº 5, p.165-188, 2014.

LE GOFF, Jacques. História e Memória. Trad. Bernardo Leitão et al. Campinas, SP: Unicamp, 1990.

MOTTA, Rodrigo Patto Sá Motta. História, memória e as disputas pela representação do passado recente. Patrimônio e memória. São Paulo: UNESP, v.9, n.1, p. 56-70, jan-jun, 2013.

NAXARA, Marcia. Traços do passado: inventariar, preservar, classificar e narrar histórias. Revista do Instituto Histórico e Geográfico Brasileiro. Rio de Janeiro, a.171, n. 448:159-177, jul./set. 2010.

NICOLAZZI, Fernando. Prefácio. In: BAUER, Carolina Silveira. Como será o passado?: História, Historiadores e a Comissão Nacional da Verdade. 1ed. Jundiaí, SP: Paco, 2017. p.712.

PEREIRA, Mateus Henrique de Faria. Nova direita? Guerras de memória em tempos de Comissão da Verdade (2012-2014). In: Varia História, Belo Horizonte, vol. 31, n. 57, p. 863902, set/dez 2015. Disponível em: http://www.scielo.br/scielo.php?script=sci_arttext\&pid=S0104-87752015000300863. Acesso em: 08/abr./2016.

PEREIRA, Nilton Mullet. Ensino de História, dever de memória e os temas sensíveis. In: Anais do II Seminário de Educação, Conhecimento e Processos Educativos. Disponível em: http://periodicos.unesc.net/seminarioECPE/index. Acesso em: 07/dez./2018.

PINHO, Ângela. Livro do Exército ensina a louvar ditadura e censura. Folha de S. Paulo, $16 / 06 / 2010$. 
PROST, Antoine. [1996] Doze lições sobre a história. Trad. Guilherme João de Freitas Teixeira. $2^{\mathrm{a}}$ ed. Belo Horizonte: Autêntica Editora, 2012.

REIS FILHO, Daniel Aarão Reis. A anistia recíproca no Brasil ou a arte de reconstruir a história. In: TELLES, Janaína (org.). Mortos e desaparecidos políticos: reparação ou impunidade. $2^{\mathrm{a}}$ ed. São Paulo: Humanitas, 2001.

REIS FILHO, Daniel Aarão Reis. [et al.] Versões e ficções: o sequestro da história. 1.ed. São Paulo: Fundação Perseu Abramo, 1997.

ROLLEMBERG, Denise. Esquecimento das memórias. In. FILHO, João Roberto Martins (org.). O golpe de 1964 e o regime militar. São Carlos, SP: Ed. UFSCAR, 2006, p. 81-91.

ROUDINESCO, Elisabeth. A análise e o arquivo. Rio de Janeiro: Jorge Zahar Ed., 2006.

RÜSEN, Jörn. Pode-se melhorar o ontem? Sobre a transformação do passado em história. In. SOLOMON, Marlon (org.). História, verdade e tempo. Chapecó-SC: Argos, 2011, p 259-290. RÜSEN, Jörn. Cultura faz Sentido: orientações entre o ontem e o amanhã. Petrópolis: Editora Vozes, 2014.

SARLO, Beatriz. Tempo passado: cultura da memória e guinada subjetiva. Trad. Rosa Freire D’Aguiar. São Paulo: Companhia das Letras/Belo Horizonte: UFMG, 2007.

SARLO, Beatriz. Paisagens imaginárias: intelectuais, arte e meios de comunicação. Trad. Miriam Senra. 1.ed. São Paulo: Edusp, 2016.

SEFFNER, Fernando; PEREIRA, Nilton Mullet. Ensino de história: passados vivos e educação em questões sensíveis. In: Revista História Hoje, v. 7, nº13, p.14-33. 2018. Disponível em: https://rhhj.anpuh.org/RHHJ/article/view/427/275. Acesso em: 07/fev./ 2019. SELIGMANN-SILVA, Márcio. Imagens precárias: inscrições tênues de violência ditatorial no Brasil. In. Estudos de literatura brasileira contemporânea, n. 43, p. 13-34, jan./jun. 2014.

SELIGMANN-SILVA, Márcio. Narrativas contra o silêncio: cinema e ditadura no Brasil. In: ; GINZBURG, Jaime; HARDMAN, Francisco Foot (org). Escritas da

violência: representações da violência na história e na cultura contemporâneas da América Latina. v.2. Rio de Janeiro: 7Letras, 2012. p.64-85.

SOUZA, Jessé. A elite do atraso: da escravidão à lava jato. Rio de janeiro: Leya, 2017.

SCHWARTSMAN, Hélio. A "história oficial" e os argumentos interessados. Folha de S. Paulo, 13/06/2010.

TELES, Edson; SAFATLE, Vladimir (Org.). O que resta da ditadura: a exceção brasileira. São Paulo: Boitempo, 2010.

TRAVERSO, Enzo. O passado, modos de usar: História, memória e política. Lisboa, Edições Unipop, 2012. 